\title{
Identificación y caracterización de las manifestaciones culturales religiosas católicas en Los Antiguos, Provincia de Santa Cruz
}

\section{Identification and characterization of the Catholic religious cultural manifestations in Los Antiguos, Province of Santa Cruz}

\author{
Jacquelina Díaz Viegas ${ }^{1}$, Mónica Norambuena ${ }^{1,2}$, Cristian Ampuero ${ }^{1,2}$ \\ jaqmaridiaz@yahoo.com.ar,mnorambuena@uarg.unpa.edu.ar, \\ campuero@uarg.unpa.edu.ar \\ ${ }^{1}$ Escuela de Geografía, Ordenamiento Territorial y Geoinformación UNPA UARG \\ ${ }^{2}$ Instituto de Ambiente, Sustentabilidad y Recursos Naturales (ICASUR), UNPA UARG
}

Recibido: 28/05/2020. Aceptado: 14/12/2020

\begin{abstract}
RESUMEN
Una importante cantidad de trabajos podrían mencionarse en torno al estudio de la religión a escalas global y local, pero casi nulos los relacionados a la provincia de Santa Cruz y particularmente a Los Antiguos. Esta localidad, se localiza a 993 km al NO de Río Gallegos, con uno de los valores más bajos en cantidad de habitantes. El presente trabajo forma parte del plan de trabajo de la estudiante de la Licenciatura en Geografía Jacquelina Díaz Viegas como integrante del Proyecto de Investigación 29 A/427-1 "La geografía de las religiones en el ejido municipal de Río Gallegos en el año 2018. La Geografía cultural en la Patagonia austral extraandina". En este caso, se presenta un estado de avance del mismo. Su objetivo es identificar la influencia territorial de la religión Católica Apostólica Romana en Los Antiguos en el marco de la Geografía cultural y de la Geografía de las religiones. Estas manifestaciones culturales religiosas católicas, se identificaron y caracterizaron a partir de lecturas comprensivas, de la observación directa, en salidas de campo y concertando entrevistas con actores clave en la localidad. Se espera contribuir con la generación de conocimiento a grupos interdisciplinarios abocados al estudio de las Ciencias Sociales, la Geografía y de las religiones, como así también a la formación profesional de la estudiante avanzada.
\end{abstract}

Palabras clave: Religión; Ejido municipal; Territorio; santos católicos y populares.

\begin{abstract}
A significant amount of work could be mentioned around the study of religion on a global and local scale. It is possible to find innumerable investigations at the local level, but almost nil those related to the province of Santa Cruz and particularly Los Antiguos. This town is located $993 \mathrm{~km}$ NW of Río Gallegos, with one of the lowest values in number of inhabitants. This work is part of the work plan of the student of the Degree in Geography Jacquelina Díaz Viegas as a member of Research Project 29 A / 427-1 "The geography of religions in the municipal ejido of Río Gallegos in 2018. Cultural Geography in the Southern Andean Patagonia". In this case, a progress status is presented. Its objective is to identify the territorial influence of the Roman Apostolic Catholic religion in the Ancients within the framework of cultural Geography and the Geography of religions. These Catholic religious cultural manifestations were identified and characterized from comprehensive readings, direct observation, field trips and arranging interviews with key actors in the locality. It is hoped to
\end{abstract}


contribute with the generation of knowledge to interdisciplinary groups dedicated to the study of Social Sciences, Geography and religions, as well as the professional training of the advanced student.

Keywords: Religion; Municipal ejido; Territory; catholic and popular saints.

\section{INTRODUCCIÓN}

El siguiente trabajo reúne un estado de avance del plan de trabajo de la estudiante avanzada de la carrera Licenciatura en Geografía, Jacquelina M. Díaz Viega, en asesoría con la codirectora del Proyecto de Investigación 29 A/427-1 "La geografía de las religiones en el ejido municipal de Río Gallegos en el año 2018. La Geografía cultural en la Patagonia austral Extraandina", Mónica V. Norambuena y un integrante del mismo, Cristian Ampuero. El proyecto de investigación antes mencionado es dirigido por Alicia P. Cáceres. En este caso, el presente trabajo, tiene como objetivo identificar la influencia territorial de la religión Católica Apostólica Romana en Los Antiguos en el marco de la Geografía cultural y de la Geografía de las religiones. Ante la escasez de estudios vinculados a estas últimas corrientes dentro de la Geografía y en relación a la escala local en la provincia de Santa Cruz, es que se propuso conocer la influencia del catolicismo en Los Antiguos.

Si bien este trabajo se enmarca en un proyecto de investigación radicado en Río Gallegos y con área de estudio en esa ciudad, la presente investigación se realiza considerando la localidad de Los Antiguos como estudio de caso significativo, el cual aportará y ampliará el conocimiento en relación al marco teórico y metodológico estudiado. Se considera al catolicismo en la localidad, ya que, junto al evangelismo, son las ramas más significativas territorialmente observadas del cristianismo, además de ser reconocidas por el Ministerio de Relaciones Exteriores y Culto. Se espera contribuir con la generación de conocimiento a grupos interdisciplinarios abocados al estudio de las Ciencias Sociales, la Geografía y de las religiones, como así también a la formación profesional de la estudiante avanzada. Este estudio se relaciona con otros que se están desarrollando en el marco del Proyecto de Investigación antes mencionado en relación a la religión católica y su influencia en el territorio de la provincia de Santa Cruz.

Estas manifestaciones culturales religiosas católicas, se identificaron y caracterizaron a partir de lecturas comprensivas, de la observación directa, en salidas de campo y concertando entrevistas con actores clave en la localidad.

Se contribuyó con la generación de conocimiento a grupos interdisciplinarios abocados al estudio de las Ciencias Sociales, la Geografía y en particular, la de las religiones, como así también a la formación profesional de la estudiante avanzada. Asimismo, se contribuyó al conocimiento a escala local de las manifestaciones culturales en relación a la religión católica en Los Antiguos.

Se pudo identificar la influencia territorial de la religión Católica Apostólica Romana en Los Antiguos en el marco de la Geografía cultural y de la Geografía de las religiones. 


\subsection{MARCO HISTÓRICO GEOGRÁFICO}

Los Antiguos se ubica en la provincia de Santa Cruz, en el departamento Lago Buenos Aires, a $\operatorname{los} 46^{\circ} 32^{\prime} \mathrm{LS}$ y $71^{\circ} 37^{\prime} \mathrm{LO}$, al noroeste de la capital provincial, sobre el límite internacional con la República de Chile. Se emplaza en la margen sur del lago Buenos Aires a 250 m.s.n.m, en los terrenos que forman el delta de la desembocadura de los ríos Jeinimeni y Los Antiguos. El departamento concentra una población de 9483 habitantes registrados en el Censo de Población, Hogares y Vivienda del año 2010 (INDEC), de los cuales 3.363 viven en Los Antiguos, la segunda localidad en importancia del departamento Lago Buenos Aires. (Díaz et al, 2013:104-106). El medio natural está condicionado por la historia geológica regional, particularmente, los eventos glaciarios cuaternarios, que modelaron el paisaje (Ramos, 1999). En ese tramo de la cordillera las alturas promedio se extienden entre los 2.000 y 2.500 m s.n.m. El relieve bajo, próximo al lago, constituye una planicie glaciolacustre, en tanto que las morrenas laterales forman las áreas con topografía más elevada, ubicándose progresivamente a alturas superiores en la medida que poseen mayor antigüedad (Pereyra et al, 2002:s/d). El clima de la región está clasificado como frío semiárido de transición (Coronato et al., 2008:45). La temperatura media anual es de $9.3^{\circ} \mathrm{C}$, con medias mensuales que varían desde $15,3^{\circ} \mathrm{C}$ en enero a $2,7^{\circ} \mathrm{C}$ en julio y una marcada amplitud respecto a las temperaturas absolutas. Debido a su latitud moderadamente alta tiene días de verano largos, alta radiación solar y baja humedad relativa, que favorece los cultivos. El viento está presente a lo largo de todo el año, dominante del cuadrante oeste. En lo que respecta a la hidrografía, destaca el lago Buenos Aires compartido con la República de Chile. Posee una superficie de $1.850 \mathrm{~km} 2$, de los cuales $841 \mathrm{~km} 2$ se localizan en Argentina. Es un lago de origen glacial, cuya cuenca de tipo exorreica desemboca en el océano Pacífico a través del río Backer. Tiene como principales afluentes los ríos Jeinimeni y Los Antiguos y el arroyo Las Chilcas. La flora, se corresponde con el distrito occidental de la provincia fitogeográfica patagónica (León et al, 1998:128), caracterizado por una estepa arbustiva graminosa en la que abundan los "coirones", con cobertura que ronda el $50 \%$. Este tipo de vegetación también ha sido denominada como "pastizal de coirón amargo" por Soriano et al. (1976), por la abundancia de esta especie (Stipa speciosa). Hacia el Oeste aparecen las primeras manifestaciones del bosque andino patagónico. (Fig. 1) 


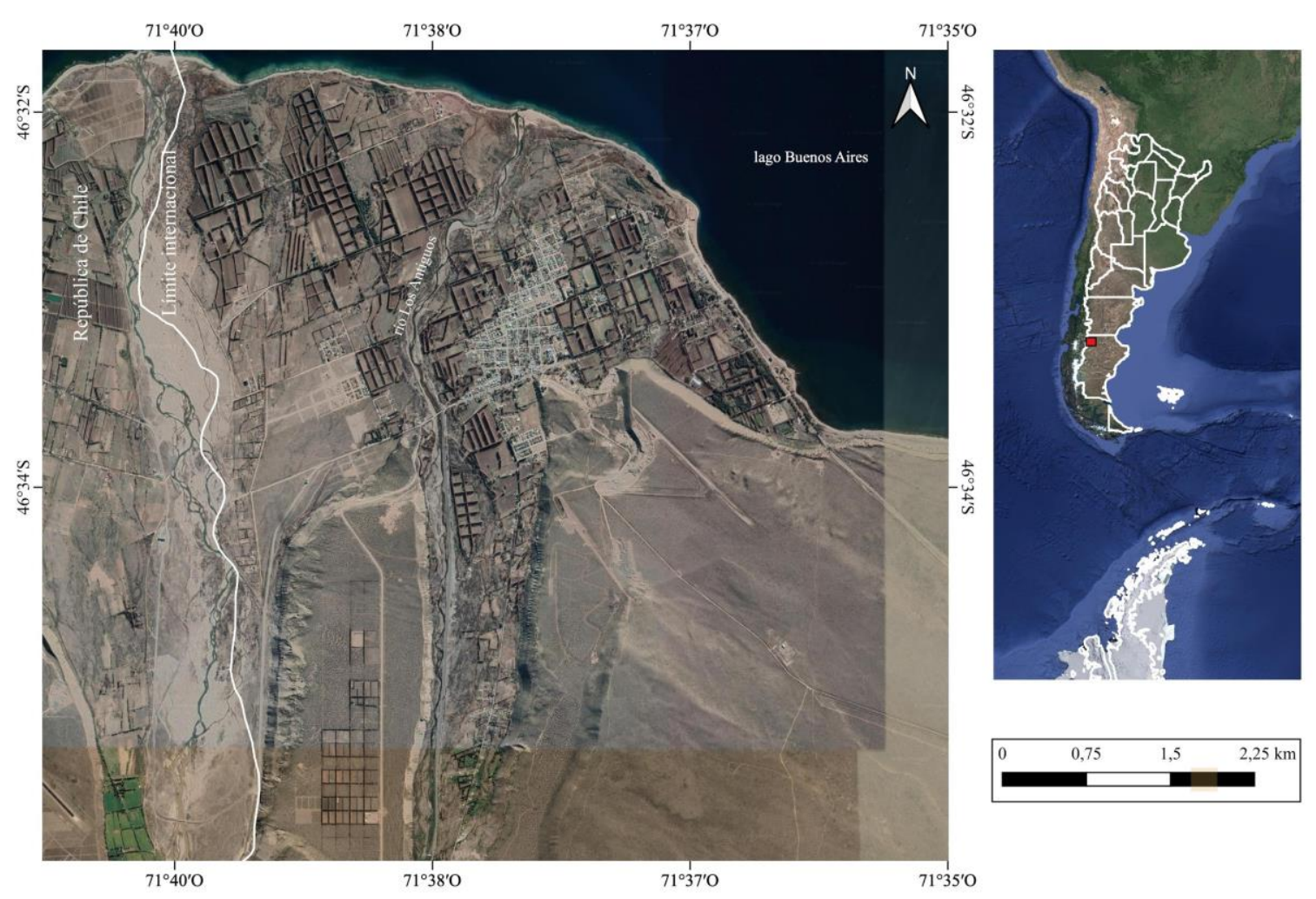

Fig. 1. Localización de Los Antiguos. Fuente: Imágen de satélite de Google Earth y bases cartográficas del IGN.

Los Antiguos y Perito Moreno son los únicos centros poblacionales que poseen infraestructura urbana o semi urbana dentro del departamento Lago Buenos Aires y están vinculados entre sí por la Ruta Provincial $\mathrm{N}^{\circ} 43$, que a su vez une la localidad de Perito Moreno con las localidades de Las Heras y Pico Truncado, hacia el este. La ruta Nacional $\mathrm{N}^{\circ}$ 40 pasa por Perito Moreno proveniente de la localidad de Río Mayo (Chubut) y continúa en dirección sur hacia el pueblo de Bajo Caracoles. A su vez, en Chile, próxima al río Jeinimeni y a Los Antiguos, se encuentra la localidad de Chile Chico, con vinculación directa por vía terrestre con la última mencionada a través de la ruta internacional Paso fronterizo Jeinimeni. Las vías de transportes son las rutas terrestres, a través de ellas, Los Antiguos se comunica directamente con Perito Moreno, Hipólito Irigoyen y Chile Chico (Chile). Por la Ruta Provincial No 43 entran los camiones que abastecen a la localidad. (Díaz et al, 2013:106,110)

En relación a la historia de la localidad, en las últimas décadas del siglo XIX, Jorge Musters y Carlos María Moyano figuran en los antecedentes de la exploración en los parajes del Noroeste santacruceño. En 1880, Moyano bautizó al lago Buenos Aires, en cuyas márgenes se levantaría años después la población. En 1897, el perito Moreno incursiona en el sector del Lago Buenos Aires, recorriendo el área cordillerana y tomando nota de accidentes geográficos, lagos y ríos, con el fin de fijar los límites con Chile y de dar a conocer la zona austral del país. Para promover la ocupación de las tierras por parte de colonos, el Estado reglamentó su distribución, lo que dio lugar a distintas legislaciones que regularon este proceso entre 1878 y 1915. (Navarro, 1998 en Díaz et al, 2013: 107)

El 11 de julio de 1921, se crea a través de un Decreto Nacional que da origen a colonias y pueblos en distintos Territorios Nacionales, la colonia Leandro N. Alem, dentro de la cual, 
años más tarde se crea la colonia mixta Los Antiguos. En esa década comienza el verdadero poblamiento del lugar con el afincamiento de pobladores en ambas márgenes del río Los Antiguos. En 1924, se reserva tierra destinada a la agricultura. En 1928, existen algunas chacras y se instala la escuela primaria y un destacamento de policía. En 1939, se procedió a la traza urbana según recomendaciones de la Gobernación del territorio. El 5 de febrero de 1948 se creó la Comisión de Fomento de Los Antiguos, fecha en que se celebra el Día del Pueblo, que fue designado municipio el 22 de febrero de 1979. (García, 2002: 659)

Los primeros colonos se establecieron en 1910. El valle de Los Antiguos, fue poblado por migrantes provenientes de Chubut y de la República de Chile. En la década de 1920, también comenzó el afincamiento de otros pobladores argentinos y de españoles que, siguiendo la onda de difusión del este, se instalaron en las márgenes del río Los Antiguos. Los primeros habitantes fueron atraídos por la posibilidad de explotar, como arrendatarios, tierras todavía libres de ocupación, a la vez alentados por el precio de la lana que había comenzado a subir. (Navarro, 1998 en Díaz et al, 2013:107)

En cuanto al crecimiento poblacional del área y la localidad de Los Antiguos, Cuadra (2000) indica que, según el Censo Nacional de Población del año 1895, el departamento Puerto Deseado, al que pertenecía en ese entonces Los Antiguos, contaba con 44 habitantes, de los cuales el $57 \%$ eran extranjeros, en su mayoría chilenos y uruguayos. Recién a partir de 1947 la población de Los Antiguos comenzó a registrarse en los censos nacionales, entre los asentamientos con menos de 500 pobladores, en ese entonces poseía 388 habitantes. A lo largo de los censos, la localidad muestra un crecimiento moderado y muy pausado al igual que la mayoría de las poblaciones ubicadas en las áreas centrales y occidentales de la provincia.

En 1960 el espacio santacruceño ya estaba organizado institucionalmente como provincia. En ese entonces, entre Los Antiguos y Perito Moreno sumaban 1587 habitantes, con valores de participación extranjera entre $25 \%$ y $31 \%$ de los cuales el país que aportaba mayores caudales inmigratorios era Chile, con el $80 \%$ del total.

Ya en 1970, sólo el 5\% del total poblacional de Santa cruz se ubicaba en el Departamento Lago Buenos Aires, con un total de 4330 habitantes. En Los Antiguos residían 614 personas. En este censo se evidencia un aumento en la población de Los Antiguos, como consecuencia del impulso de la actividad agropecuaria.

En 1980, Los Antiguos contaba con 777 habitantes, mostrando un crecimiento moderado de su población. El Departamento Lago Buenos Aires se ubicó entre los departamentos de mayor población argentina, y un alto porcentaje de nacidos en Santa Cruz (entre 79 y 86\%), con alrededor de un $19 \%$ de extranjeros.

Para 1991 Los Antiguos ascendió su población a 1462 habitantes, para ese entonces la frutihorticultura, el cultivo de plantas forrajeras y un incipiente movimiento turístico en el área seguían fortaleciéndose. Así, Los Antiguos incrementaba su peso demográfico en forma considerable. (Cuadra, 2000)

En el siglo XXI, la localidad presentó incremento de población, se registraron 2047 habitantes en el 2001 y 3363 en el 2010 (INDEC, 2001, 2010). 


\subsection{MARCO CONCEPTUAL}

Dentro de este apartado, se consideraron como relevantes los siguientes conceptos:

Iglesia Católica Apostólica Romana: (También se le conoce como «Catolicismo», «Iglesia Católica», «Iglesia Católica Romana» o «Iglesia de Roma».) La mayor de las iglesias del cristianismo histórico. De acuerdo con la tradición de esta iglesia, Jesucristo la fundó y el apóstol Pedro fue su primer papa (título que se le da a la cabeza visible de la iglesia). Los cristianos del período posterior a la iglesia primitiva empezaron a identificarse en numerosas regiones como católicos o miembros de la Iglesia Católica o Universal, para distinguirse de varios grupos considerados heréticos. Algunos historiadores seculares y casi todos los historiadores protestantes entienden que esta iglesia surgió como resultado de la evolución de la Iglesia Católica Antigua hacia una organización centralizada con sede en Roma. Lo anterior tiene relación con el proceso de oficialización del cristianismo en los siglos IV y V, iniciado con Constantino (que lo favoreció) y llevado hasta sus últimas consecuencias por sus sucesores (que lo convirtieron en religión oficial del Imperio). Algunos mencionan al papa León I como el que consolidó el poder de la sede romana en el siglo V, mientras otros, prefieren el pontificado de Gregorio I (siglos VI y VII) como período que indica el inicio del catolicismo romano en la forma que actualmente se conoce, pero esto es discutible. Los católicos romanos aceptan siete sacramentos, la intercesión de la virgen María y de los santos, el purgatorio (estado intermedio entre el cielo y el infierno), el celibato sacerdotal (por lo menos en su rito latino u occidental, predominante en la iglesia), la existencia de órdenes monásticas de hombres y mujeres, el carácter sacerdotal del ministerio de la iglesia y hacen énfasis en el sacrificio de la misa. Aceptan veintiún concilios ecuménicos o de toda la iglesia, el primero de ellos es el de Nicea (325 d.C.). La iglesia está organizada en forma jerárquica con el papa a la cabeza y las diócesis gobernadas por obispos (algunos de ellos son denominados arzobispos). El papa es elegido por un colegio de prelados llamados cardenales y se le considera infalible desde 1870. La Ciudad del Vaticano (situada en una de las colinas de Roma) es considerada como la Santa Sede por los católicos y mantiene relaciones con la mayoría de las naciones. El catolicismo está extendido por casi todo el mundo y prevalece en la mayor parte de Europa y en Iberoamérica, aunque va perdiendo influencia en estos territorios. Ha mejorado sus relaciones con las iglesias orientales u ortodoxas y con algunas denominaciones protestantes históricas. Desde el Concilio Vaticano II, iniciado en 1963, se han introducido numerosos cambios en la iglesia, incluyendo la celebración de la misa en lengua vernácula (anteriormente se celebraba en latín) (Ramos, 2016:43-44)

Parroquia: según el diccionario on line Definciones.de, el término parroquia procede del latín parochĭa y que tiene su antecedente más lejano en un vocablo griego. Puede utilizarse en el ámbito religioso para nombrar al templo donde se brinda atención espiritual a los creyentes y se ejerce la administración de los sacramentos. El concepto también permite hacer referencia a la comunidad de fieles y a la región territorial que depende de una determinada jurisdicción espiritual". (Parroquia (2019) En Definiciones.de, 2019 recuperado de https://definicion.de/parroquia/)

\subsection{MARCO TEÓRICO}

La Geografía Cultural, ha sido una de las ramas menos desarrolladas dentro de la ciencia geográfica. En 1931, Carl Sauer decía que "la geografía cultural es tan sólo un capítulo de la geografía en su sentido más amplio y siempre el último capítulo" (Gómez Mendoza J. et al, 1982: 351). La Geografía cultural, Kulturgeographie, fue introducida al léxico geográfico por 
Fiedrich Ratzel, geógrafo alemán del siglo XIX. Sin embargo, como disciplina, se cimentó en la segunda década del siglo XX. Su primer auge se asocia invariablemente a Carl Sauer y a su liderazgo en la escuela de Berkeley. La Universidad de California, donde trabajó desde 1923 hasta 1957, le ofreció un medio adecuado, donde las relaciones interdisciplinarias, en particular con los antropólogos fueron de gran importancia para él. Sauer, de ascendencia alemana, se vio influido por las ciencias históricas, geográficas y culturales alemanas, a través de autores como Eduard Hahn, Alfred Hettner y Fiedrich Ratzel; de norteamericanos como George Marsh y de británicos como Vaughan Cornish y H.J. Fleure (Sauer, 1974; Jackson, 1992: 11; citado por López Levi L., 2010:211). Un punto de partida importante y documento central en su pensamiento fue "La Morfología del Paisaje", escrita por él en 1925, donde define al paisaje como la forma de la tierra (land shape), misma que depende, en su proceso, no sólo de los elementos físicos, sino también de los culturales (Sauer, 1925; citado por López Levi L., 2010:211).

López Levi L. (2010) menciona que la cultura fue, por mucho tiempo, un campo de estudio básicamente de los antropólogos; para los geógrafos se trataba de una más de las características de las regiones. De manera tal que se la consideraba junto con la geología, la vegetación, el clima, el uso del suelo y las actividades económicas. Cultura, en el marco de un listado de elementos del territorio, generalmente se refería a razas, grupos étnicos, religiones y lenguas; así se transmitió de maestro a alumno por generaciones. En investigación, a pesar de que muchas veces se definía al grupo social analizado en función de estas variables -por ejemplo, grupos indígenas-, ello no significaba que hubiese una perspectiva cultural del problema estudiado. Lo anterior no se debía a planteamientos mal logrados, sino simplemente a que dicho enfoque no era la intención con la que se abordaban los estudios geográficos de la época. En los años setenta del siglo XX, la Geografía Cultural vislumbró nuevas perspectivas a través de los geógrafos humanistas, entre los que destacó Yi Fu-Tuan, norteamericano de origen chino. (López Levi L., 2010: 212-213)

Asimismo, no se pueden dejar de mencionar los aportes teóricos del geógrafo francés Paul Claval, que en su obra Geografía Cultural (1999), ofrece un reencuentro crítico con la tradición disciplinaria de la Geografía, así como con sus expresiones más novedosas. En esta obra, literatura casi obligatoria en cuanto al estudio de la geografía Cultural, el autor hace uso de su bagaje como historiador de la Geografía para brindar un sintético pero esclarecedor estado del arte, que recorre las diversas corrientes de la Geografía Cultural desde su nacimiento hasta fines del siglo XX, momento en que aparece su obra. A medida que esta es desarrollada, se examinan las interrelaciones que se establecen entre la cultura y los demás factores que, desde el punto de vista del autor, inciden en la estructuración de la sociedad en su relación con el territorio. Los capítulos finales de la obra de Paul Claval, transitan los problemas contemporáneos que constituyen la base del renovado interés por esta rama de la Geografía, echando luz sobre las huellas culturales dejadas por la geopolítica de la modernidad en los últimos siglos. El encuentro y el choque de culturas, el colonialismo y la occidentalización del mundo, el desarrollo y el subdesarrollo, así como las nuevas formas de transmisión cultural, son leídos desde fenómenos concretos de hibridación o de resistencia cultural: el sincretismo religioso, la emergencia de los nacionalismos y los fundamentalismos, las nuevas utopías políticas, las modificaciones en el gusto o el fin de las cosmovisiones tradicionales (De la Fuente L. A., 2000: 572).

Por otra parte, dentro del desarrollo de la Geografía en la Argentina, la Geografía Cultural ha tenido, a lo largo del siglo XX, escaso desarrollo. A principios de ese siglo, la línea de enseñanza e investigación ha estado bajo la influencia de una Geografía más naturalista, 
comenzando hacia mediados del siglo XX un desarrollo más vinculado a la Geografía Social. En este sentido, geógrafos como Elena Chiozza fueron referentes del desarrollo de esta Geografía con su obra "El País de los Argentinos", lo que causó discrepancias con el tinte naturalista que poseía hasta el momento la disciplina. Más tarde, el advenimiento de dictaduras militares, con su máxima expresión en la última situada temporalmente entre 1976 y 1983, llevó a que los referentes de la Geografía social minimizaran sus obras y dejarán de tener participación en las cátedras de las carreras de Geografía en universidades públicas y migraran hacia institutos y universidades privadas. (Zusman P. et al, 2007: 784-788).

Hacia finales del siglo XX, en la década de 1990, la Geografía Social tuvo mayor preeminencia que la Cultural. Como se mencionó anteriormente, referentes como Paul Claval, con su obra "La Geografía Cultural" del año 1999, han sido un gran aporte a la disciplina en el país, pero ha tenido escaso impacto en el desarrollo de investigaciones locales. La articulación entre migración, género y religión en la conformación de lugares es una línea que se ha comenzado a desarrollar desde finales de la década de 1990 y ha tomado relevancia a partir de los 2000 y hasta la actualidad, entre otras temáticas vinculadas a la Geografía Cultural. (Zusman P. et al, 2007: 792)

En el mundo y en la República Argentina, en las últimas décadas, en el interior de la disciplina y especialmente en el mundo anglosajón, se han venido desarrollando intentos para la construcción de una "nueva Geografía Cultural", emparentada al auge de los estudios culturales, conjunto de trabajos heterogéneos interesados por el análisis de una amplia gama de manifestaciones que abarcan desde la literatura clásica o la música popular, hasta los hábitos de consumo urbanos o las conductas de interrelación personal. La vida cotidiana en las ciudades modernas ha significado un gran foco de atención para muchos de dichos estudios. (De la Fuente L. A., 2000: 573).

Dentro de esta tendencia, se encuentra uno de los temas de interés dentro de la Geografía Cultural, la religión y más precisamente, la Geografía de las Religiones. En este sentido, la Geografía de las Religiones tradicionalmente ha tratado los temas de manera descriptiva, pero en los último años, en palabras de Santarelli y Campos (2011), hay una nueva mirada de la Geografía de las Religiones como enfoque emergente vinculado a la renovada Geografía Cultural, que aporta nuevos conceptos y categorías de análisis para comprender las diversas relaciones entre las sociedades y el espacio local vinculadas a prácticas basadas en el ejercicio de la fe, no solo en su tratamiento sino también en la enseñanza (Santarelli y Campos, 2011:2), En relación a las formas de tratar la influencia de las religiones y la fe en el territorio, se pueden considerar trabajos cartográficos, aportes teóricos conceptuales en relación al territorio, entre otros. Si bien las investigaciones tratan en general la Geografía de las Religiones y su desarrollo e impacto territorial, son los trabajos a escala local los más realizados. El presente trabajo posee características de los desarrollados a escala local.

\section{RESULTADOS ANÁLISIS Y DISCUSIÓN}

\subsection{MATERIALES Y MÉTODO}

Las manifestaciones culturales religiosas católicas presentes en la localidad de Los Antiguos, se identificaron y caracterizaron a partir de, primero, la búsqueda de literatura científica geográfica relacionada a la geografía cultural y a la geografía de las religiones; posteriormente, se procedió a las lecturas comprensivas de dicho material bibliográfico 
específico. De los artículos relevados y seleccionados para este trabajo, se reconocieron las ideas principales de cada autor consultado; asimismo, se identificaron conceptos relevantes relacionados a la Geografía cultural, a la Geografía de las religiones y a la religión católica. Se realizaron resúmenes, mapas conceptuales y cuadros comparativos, con el propósito de determinar las similitudes y diferencias entre los distintos autores y, de esa manera, facilitar la realización del marco teórico-conceptual.

Por otro lado, se recurrió en cinco oportunidades a la observación directa en salidas de campo realizadas dentro de la localidad de Los Antiguos y en los alrededores -rutas hacia Perito Moreno y hacia la República de Chile-. En estas salidas de campo, se procedió a registrar en una planilla, las manifestaciones culturales católicas presentes en las rutas y dentro de la localidad, localizando con gps cada una de las mismas. Asimismo, se generó un registro fotográfico de, por ejemplo, imágenes de vírgenes, santos, murales, pequeños predios con altares dedicados a figuras de culto de la religión católica reconocidas por la Iglesia y santos de religiosidad popular, como el Gauchito Gil.

Por último, se concertaron entrevistas informales con actores clave de Los Antiguos, referentes del catolicismo. Se seleccionó a los entrevistados: el sacerdote a cargo de la parroquia, referentes de entidades públicas como escuelas, hospital, entre otros. Se elaboró una guía con preguntas para conocer, en el caso del sacerdote, las actividades que se realizan, los espacios con que cuenta la Iglesia en la localidad, la cantidad de fieles que concurren frecuentemente, entre otra información de interés. Asimismo, se definieron preguntas para los referentes de entidades públicas en las que se encuentran imágenes relacionadas al catolicismo en espacios públicos. Se realizó el registro escrito de las entrevistas informales realizadas.

\subsection{RESULTADOS}

La presencia del catolicismo en Los Antiguos, puede identificarse partiendo de la localización del único templo dedicado a esta religión, el mismo data de entre 1955 y 1960 aproximadamente. En el año 2011, se lo comienza a considerar como una parroquia. En ese mismo año, se construye la vivienda parroquial. Anteriormente, era una capilla perteneciente a la parroquia de Perito Moreno.

El templo en la localidad se denomina parroquia Sagrado Corazón de Jesús, patrono de Los Antiguos (Figs. 2, 3 y 4). De allí su nombre y las estatuillas en diferentes lugares dentro del templo y en la localidad. Posee un salón de usos múltiples ubicado dentro del mismo terreno, en su parte posterior. En este salón se realizan actividades como: catecismo, encuentros, celebraciones $\mathrm{y}$, en donde además funciona Caritas, organización dedicada a atender cuestiones sociales. Esta parroquia depende del obispado de Río Gallegos y todos los domingos y el primer viernes de cada mes oficia misas. 

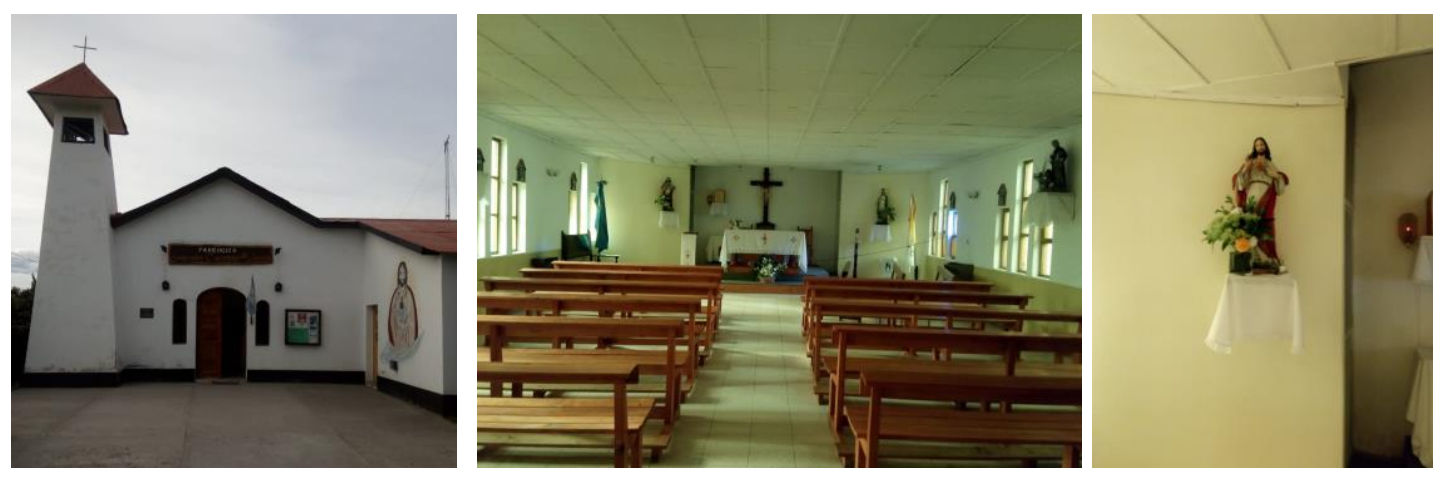

Fig. 2. Parroquia Sagrado Corazón de Jesús. Fig. 3. Interior de la parroquia. Fig. 4. Imagen del Sagrado Corazón de Jesús. Fuente: Jaquelina Díaz Viega.

La parroquia Sagrado Corazón de Jesús, se ubica en la calle Cruz del Sur, el fondo del patio en el que se encuentra el templo limita con la calle Patagonia Argentina. Corresponde este sector al casco antiguo de la localidad. La parroquia está rodeada por la primera escuela primaria (EPPN 17 "Policía Federal Argentina", del año 1932), la Plaza Principal "San Martín” y el hospital local (construcción del año 1992).

Entre las principales manifestaciones culturales católicas que se vinculan a la parroquia y que se desarrollan en la localidad se pueden mencionar:

- Viernes Santo, Vía Crucis, la imagen de la Virgen María sale desde el puente del río Los Antiguos, en este lugar se encuentra la primera estación del Vía Crucis, los peregrinos paran y pasan por las catorce estaciones que representan los momentos de la pasión, muerte y crucifixión de Cristo hasta llegar al Cristo Redentor, sobre la ruta hacia Chile Chico, justo en el límite internacional.

- 8 de diciembre: día de la Inmaculada Concepción, peregrinación desde la parroquia a la virgen María sobre ruta provincial $N^{\circ} 43$. Se recorren unos 13 kilómetros. Si bien no son muy numerosos los peregrinos que acompañan a la Virgen María en el recorrido, si son más los que de forma particular durante esa jornada peregrinan hacia la Virgen.

- Entre el 26 y 29 de junio, se realiza una actividad llamada Procesión, en la que se comparten en la parroquia, diferentes actividades en torno al catolicismo.

\section{- 25 de diciembre: misa y festejos por el "nacimiento del niño Jesús".}

Por último, la parroquia reúne en promedio entre 80 y 90 personas por misa, de las cuales un $70 \%$ asisten de manera permanente. El padre Luis Bicego menciona al respecto, “...en otros tiempos venía más gente", en alusión a que, en los últimos años, personas que profesaban la fe católica han cambiado de religión, eligiendo el evangelismo o profesando su fe hacia santos populares. El promedio de los bautismos es de 40 por año, aproximadamente, y los casamientos es de uno a tres anuales. Al catecismo asisten aproximadamente 15 niños por año. Con relación a los difuntos, el sacerdote a cargo de la parroquia menciona que “...generalmente los familiares llaman para realizar una misa en la sala velatoria, aunque esos familiares sean creyentes y no asistan a la parroquia. También se da el caso de familiares que llaman a pastores para lo mismo", nuevamente, el entrevistado hace referencia a la elección de otra religión dentro del cristianismo, el evangelismo y sus representantes para acciones que en décadas atrás eran practicadas por el sacerdote católico. 
Si bien se identifican otros movimientos religiosos que se encuentran presente en la localidad, en este trabajo se han considerado sólo las prácticas vinculadas a la fe católica. Esta decisión se basó en la representación territorial de las religiones reconocidas por el Ministerio de Relaciones Exteriores y Culto, de estas, se seleccionó dentro del cristianismo al catolicismo y al evangelismo. Con base a esta información, y otras antes mencionadas, se seleccionó a Los Antiguos como estudio de caso. Es por esta razón que se destaca al catolicismo sobre otras prácticas, otros templos, otras acciones de otras religiones en la localidad practicadas por la población.

En junio de 2014 la Parroquia Sagrado Corazón de Jesús-Los Antiguos, formó un grupo público en la red social Facebook, que en la actualidad posee 292 miembros.

Se pueden encontrar otras manifestaciones culturales de la religión católica en la localidad, en diferentes espacios públicos. En la Municipalidad, en el patio interno del edificio, la imagen del Sagrado Corazón de Jesús. La misma se instaló en ese lugar en el año 1997, en el actual edificio del Municipio. En la Comisaría Cabo Enrique Grippo está presente una imagen de la Virgen María desde el año 2007, momento en el que se amplió la comisaría (Fig. 5). En el edificio de la Aduana (Paso Fronterizo Río Jeinemeni) es visible una imagen del patrono de la localidad, el Sagrado Corazón de Jesús desde el año 2015. Esta misma imagen está en la estación de Bomberos desde el año 2011, también se instaló un crucifijo en la entrada del cuartel y algunos cuadros religiosos en la sala de espera desde 2007, que es cuando se inauguró y puso en funcionamiento el edificio. El Hospital Seccional Dr. Reynaldo A. Bimbi posee la imagen del Sagrado Corazón de Jesús. Aunque no es común encontrar imágenes religiosas en los establecimientos educativos provinciales, en la Escuela Primaria Provincial $\mathrm{N}^{\circ} 17$ Policía Federal Argentina se encuentra la imagen de la Virgen de Luján en la Dirección; de esta se desconoce el origen y el año en que se instaló. En el mismo establecimiento educativo, además, existe un cuadro y un crucifijo en la Secretaría en la misma situación, desconocimiento del origen y año.

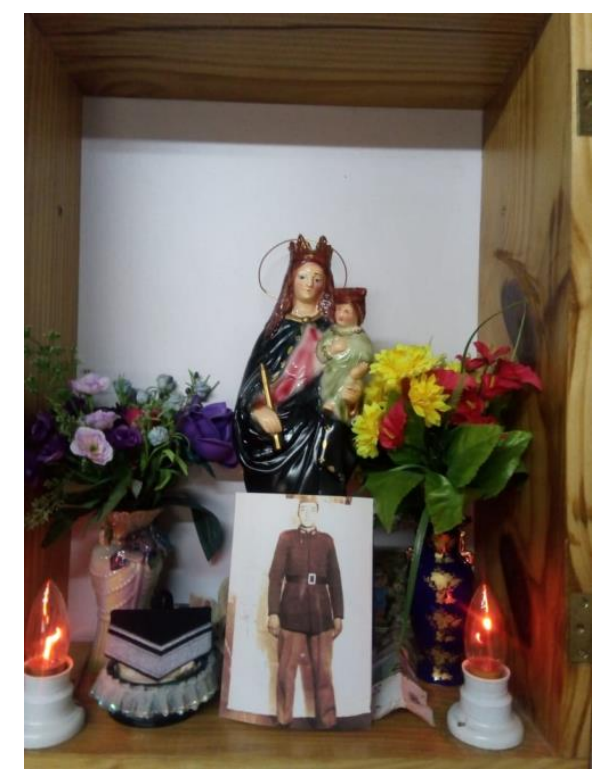

Fig. 5. Virgen María en la Comisaría Enrique Grippo. Fuente: Jacquelina Díaz Viegas

La implantación del nombre "San Juan Bosco" a la Ruta Provincial No 43, refleja la influencia de la religión católica en la localidad de Los Antiguos, en el norte de la provincia 
de Santa Cruz y en la región patagónica. Sobre esta ruta, cruzando el río Los Antiguos, se ubica una imagen de la Virgen María, la cual fue colocada por el padre Gori en el año 1955, aproximadamente. Se trata de una imagen donada por el señor Francisco Speckbacker, quien la destinó a Gendarmería, pero finalmente se erigió en ese lugar. El cuidado y mantenimiento de la imagen está a cargo de Gendarmería Nacional Argentina. Por otra parte, por la misma ruta en dirección al límite internacional con la República de Chile, se encuentran las 14 estaciones que reflejan la pasión, muerte y crucifixión de Cristo.

Se encuentran sobre la RP 43 otras imágenes representativas de la religión católica, como la de Ceferino Namuncurá, beatificado en el año 2007 y, de la religiosidad popular, por ejemplo, la difunta Correa y el Gauchito Gil, imágenes que forman parte del paisaje sobre la ruta.

La imagen del Gauchito Gil, es una de las que más se repite sobre la RP 43 (Fig. 6) y en Los Antiguos. El santuario más grande se ubica a $40 \mathrm{~km}$ sobre la RP 43 en dirección hacia Perito Moreno. Otro santuario está presente sobre la misma ruta a unos 10 kilómetros y un tercer lugar de veneración de la imagen, dentro de la localidad.

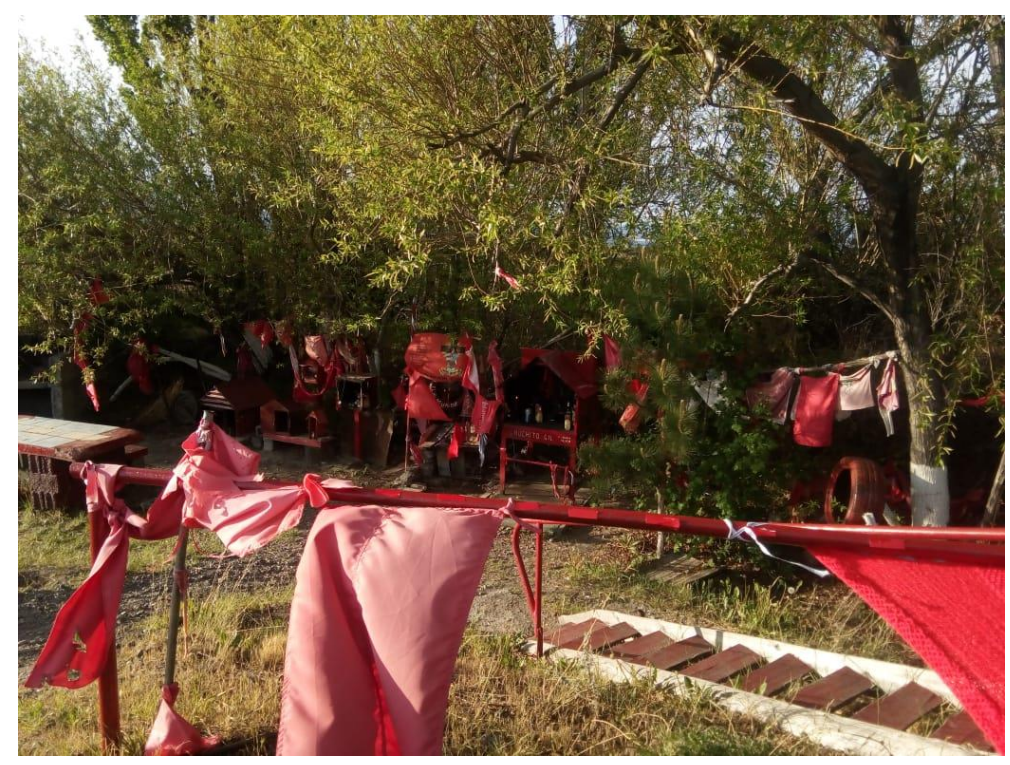

Fig. 6. Gauchito Gil sobre RP 43. Fuente: Jaquelina Díaz Viegas.

\subsection{DISCUSIÓN}

La Geografía Cultural, ha sido una de las ramas menos desarrolladas dentro de la ciencia geográfica. En Argentina, ha tenido escaso desarrollo a lo largo del siglo XX, situación que comienza a cambiar en el siglo XXI. Enmarcada en la rama cultural de la Geografía, las religiones y más precisamente la Geografía de las religiones, comenzaron a abrirse camino con investigaciones que, en su mayoría se orientan hacia los estudios locales.

En este sentido, a escala local, considerando a Los Antiguos, no existen precedentes de trabajos que se aborden desde este marco teórico.

Luego de la descripción general de la presencia del catolicismo en Los Antiguos, es posible relacionar conceptos centrales dentro de la Geografía de las Religiones con el área de estudio. 
El espacio sagrado, entendido según Zeny Rosendahl (2002) citado por Santarelli y Campos (2011:3) "como ...un campo de fuerzas y de valores que eleva al hombre religioso por encima de sí mismo,... en cuanto expresión de lo sagrado, que posibilita al hombre entrar en contacto con una realidad trascendente llamada dioses en las religiones politeístas y Dios en las monoteístas". En Los Antiguos, esta definición puede entenderse, en relación al catolicismo, en las prácticas que involucran al ejido municipal y la veneración de Dios, Cristo, diferentes vírgenes, santos -el mismo patrono de la localidad: el Sagrado Corazón de Jesús-, incluso santos de la religiosidad popular, Gauchito Gil, Difunda Correa; presentes no solo en edificios públicos, sino también en espacios públicos más allá de los límites territoriales locales, la RP $\mathrm{N}^{\circ} 43$, por ejemplo. La parroquia dedicada al Sagrado Corazón de Jesús también entra en esta categoría.

La estructura socioreligiosa, es el resultado de la interacción de los elementos fundamentales de una religión, entre ellos, la devoción, las ceremonias, los mitos. En este caso, uno de los elementos identificables es la devoción hacia Dios Padre, Hijo, Espíritu Santo y las deidades católicas y populares antes mencionadas, presentes de manera visible en el área de estudio, el ejido municipal de Los Antiguos, en sectores en los que se pueden observar altares dedicados a Ceferino Namuncurá, al Gauchito Gil, entre otros. En la parroquia, además de la imagen del Sagrado Corazón de Jesús, se observan otras de la virgen María y San Cayetano; en lugares públicos, como la escuela, el hospital o la comisaría, se observan imágenes que refieren a la devoción. El único templo dedicado al catolicismo en Los Antiguos, concentra las actividades tradicionales de la liturgia católica. El número de fieles católicos que asisten de manera permanente a las misas y otras actividades, podría decirse que es bajo (80/90 personas) en relación a la cantidad de habitantes que posee la localidad (3.363 según Censo de Población, Hogares y Vivienda del año 2010, INDEC). Existen fieles que no frecuentan el templo, pero hacen uso de los servicios que están a cargo de la Iglesia Católica, por ejemplo, los ritos funerarios. Asimismo, se observan ceremonias, presentes en fechas significativas para el catolicismo, como el Vía Crucis en viernes santo que recorre cada estación emplazada sobre la RP 43. Estos elementos junto a las prácticas que fieles y grupos religiosos - peregrinación, procesión, misas- se desarrollan en el marco de una acción evangelizadora.

Dentro de los geosímbolos (lugares, itinerarios, objetos significativos dentro de la religión) uno de los más significativos en Los Antiguos es la RP 43, convertida de manera temporal en un "itinerario sagrado" al momento de recorrer cada una de las estaciones del Vía Crucis cada viernes santo de cada año por los peregrinos que paran y pasan por cada una de las catorce estaciones que muestran el padecimiento, muerte y crucifixión de Cristo. Otro geosímbolo es la parroquia dedicada al patrono de la localidad, el Sagrado Corazón de Jesús, el cual es un espacio puntual y único dentro de la localidad. Los altares espontáneos levantados en diferentes sectores de la localidad, dedicados a los santos, integran esta categoría.

\section{CONCLUSIONES}

A partir de esta investigación, se contribuye al conocimiento a escala local de las manifestaciones culturales en relación a la religión católica en Los Antiguos.

Se pudo identificar la influencia territorial de la religión Católica Apostólica Romana en Los Antiguos en el marco de la Geografía cultural y de la Geografía de las religiones. 
La presencia de un templo dedicado a esta religión, las imágenes presentes en edificios y espacios públicos de imágenes reconocidas o no por el catolicismo, las acciones que tienen lugar en determinados meses del año coincidentes con fechas significativas de la liturgia católica, el reconocimiento a través de la imposición de nombres con santos católicos a elementos de implantación lineal, como la RP 43, son solo algunos de los componentes que permiten afirmar que hay una influencia del catolicismo en el área de estudio.

Se trata de una investigación en curso, por lo que a lo largo de la misma se pueden identificar fortalezas presentes en el trabajo de campo realizado, como el acercamiento a actores clave del catolicismo en Los Antiguos, el acceso a los espacios públicos a fin de obtener un registro fotográfico de imágenes veneradas por la población.

Por otra parte, a medida que se avance en el plan de trabajo de la investigación, se espera contar con cartografía que evidencie la presencia, no solo del catolicismo en Los Antiguos, sino de otras religiones en la localidad.

Por último, se destaca que este trabajo contribuye con la generación de conocimiento dirigido a grupos interdisciplinarios abocados al estudio de las Ciencias Sociales, la Geografía y, particularmente, de la Geografía de las religiones.

\section{AGRADECIMIENTOS}

Se agradece al sacerdote a cargo de la parroquia Sagrado Corazón de Jesús, el padre Luis Bicego y vecinos de Los Antiguos, como Patricia Avendaño, Catalina Speackbeacker, Myriam de Mendieta y Fabiana Ayala por aportar información de interés para realizar este trabajo.

\section{REFERENCIAS}

CENSO NACIONAL DE POBLACIÓN, HOGARES Y VIVIENDAS (2010). Censo del Bicentenario. INDEC. https://www.indec.gob.ar/ftp/cuadros/poblacion/censo2010_tomo1.pdf CLAVAL, P. (1999). Los fundamentos de la geografía cultural. Doc. Anál. Geogr. 34. Páginas $25-$ 40. Disponible en http://age.ieg.csic.es/hispengeo/documentos/clavalcultural.pdf

CORONATO, A., y RABASSA, J. (2002). Glaciaciones en el cenozoico tardío. En: Halller, (Ed). Relatorio del XV Congreso Geológico Argentino. Geología y recursos naturales de Santa Cruz. Parte I, Cap.19: El Calafate.

DE LA FUENTE, L. A. (2000). Reseña de "La geografía cultural" de Paul Claval. Economía, Sociedad y Territorio, vol. II, núm. 7, enero-junio, 2000, pp. 571-574 El Colegio Mexiquense, A.C. Toluca, México Disponible en: http://www.redalyc.org/articulo.oa?id=11100707

DÍAZ, J., MAZZONI, E. y DIEZ, P. (2013). Problemáticas ambientales en el área de Los Antiguos, Provincia de Santa Cruz. ICT-UNPA-65-2013 ISSN: 1852-4516 Aprobado por Resolución $\mathrm{N}^{\circ}$ 0651/13 R-UNPA. https://doi.org/10.22305/ict-unpa.v5i2.74

GÓMEZ MENDOZA, J., MUÑOZ JIMÉNEZ, J., ORTEGA CANTERO, N. (1982). El pensamiento geográfico. España. Editorial Alianza Universidad Textos.

LEÓN, R., BRAND, D., COLLANTES, M., PARUELO, J. y SORIANO, A. (1998). Grandes Unidades de vegetación de la Patagonia extra andina. Ecología Austral 8:125-144. Buenos Aires. 
LÓPEZ LEVI, L. (2010). La geografía cultural en México: entre viejas y nuevas tendencias en: Hiernaux Daniel (director) Construyendo la geografía humana. Universidad Autónoma Metropolitana-Iztapalapa / Anthropos. ISBN: 978-84-7658-962-5. Págs. 205-228.

PEREYRA, F., FAUQUÉ, L. y GONZÁLEZ DÍAZ, E. (2002). Geomorfología. En: Haller, (Ed). Relatorio del XV Congreso Geológico Argentino. Geología y recursos naturales de Santa Cruz. Parte I, Cap21: El Calafate.

RAMOS, M. A. (2016). Nuevo diccionario de religiones, denominaciones y sectas. Disponible en http://www.medioscan.com/pdf/religionesysectas.pdf

RAMOS, V. A. (1999). Evolución tectónica de la Argentina. En: R. Caminos Ed.Geología Argentina. Instituto de Geología y Recursos Minerales, Anales 29 (24): 715-789, Buenos Aires.

SANTARELLI, S., CAMPOS, M. (2011). Geografía de las Religiones, Espacios Locales y subjetividad. Una nueva mirada en la enseñanza universitaria. Revista Geográfica de América Central, vol. 2, julio-diciembre, 2011, pp. 1-19 Universidad Nacional Heredia, Costa Rica. Disponible en http://www.revistas.una.ac.cr/index.php/geografica/article/view/2599

SORIANO, A., ALIPPE, L., SAlA, O., SCHLICHTER, T., MOVIA, C., LEÓN, R., TRABUCCO, R. y DEREGIBUS, V. (1976). Ecología del pastizal de coirón amargo (Stipa spp.) del Sudoeste de Chubut. Academia Nacional de Agronomía y Veterinaria 30:1-13

ZUSMAN P., CASTRO H., SOTO M., (2007). La Geografía Cultural y social en Argentina: antecedentes y tendencias recientes. Revista Social and Cultural Geography. Londres. Pág. 775-798

SITIOS WEB

Parroquia (01/12/2019) En el diccionario on line Defincion.de recuperado de https://definicion.de/parroquia/ 